Published in final edited form as:

Inflamm Bowel Dis. 2010 February ; 16(2): . doi:10.1002/ibd.20992.

\title{
Crohn's Disease Is Associated With Restless Legs Syndrome
}

\author{
Leonard B. Weinstock, MD ${ }^{1,2}$, Brian P. Bosworth, MD $^{3}$, Ellen J. Scherl, MD ${ }^{3}$, Ellen Li, MD ${ }^{1}$, \\ Ugonna Iroku, MD ${ }^{3}$, Melissa A. Munsell, MD $^{4}$, Gerald E. Mullen, MD $^{4}$, and Arthur S. Walters, \\ MD $^{5}$ \\ ${ }^{1}$ Washington University School of Medicine, MO \\ ${ }^{2}$ Specialists in Gastroenterology, LLC, St Louis, MO \\ ${ }^{3}$ Weill Cornell Medical Center, New York, NY \\ 4Johns Hopkins Medical School, Baltimore, MD \\ ${ }^{5}$ Vanderbilt University, Nashville, TN
}

\begin{abstract}
Extraintestinal manifestations of Crohn's disease (CD) have not previously included the central nervous system (CNS). Restless legs syndrome (RLS) is a CNS disorder that is either idiopathic or secondary to a number of diseases. The aim of this study was to determine if RLS was associated with $\mathrm{CD}$ because both are associated with iron deficiency, inflammation, and bacterial overgrowth. Consecutive $\mathrm{CD}$ outpatients $(\mathrm{N}=272)$ were prospectively surveyed at 4 centers for criteria for RLS. Incidence (having RLS at any point in time), prevalence (having RLS at time of survey), clinical characteristics, risk factors, and potential qualitative relationship between RLS and gastrointestinal symptoms were queried. Incidence of RLS in patients with CD was $42.7 \%$. Prevalence was $30.2 \%$ compared with $9 \%$ of spouses. Crohn's disease patients with and without RLS had a mean age of 46.8 vs 42.6 years, small intestine involvement in $77.9 \%$ vs $66.7 \%$, colon involvement in $39.7 \%$ vs $63.2 \%$, and prior iron deficiency anemia in $49.3 \%$ vs $33.1 \%$. There was no difference between the CD groups with respect to current iron deficiency, RLS family history, or rare prevalence of concomitant RLS disorders. In $91.8 \%$ of patients with RLS and CD, RLS started during or after the onset of CD diagnosis. Among 73 patients with RLS, 67 (44.5\%) stated there was a relationship between qualitative RLS symptom improvement with overall CD symptom improvement. These results demonstrate that RLS occurs frequently in CD and appears to be a possible extraintestinal manifestation. The potential relationship of RLS with CD activity warrants further investigation.
\end{abstract}

\section{Keywords}

Crohn's disease; restless legs syndrome; iron deficiency; bacterial overgrowth

\section{INTRODUCTION}

Crohn's disease (CD) is a chronic, inflammatory disease of the gastrointestinal (GI) tract that primarily affects the small intestine and colon $(1,2)$. The etiology of CD is not fully understood but most likely results from abnormal mucosal immune responses stimulated by intestinal bacteria in genetically susceptible individuals $(1,3)$. Although in most cases CD mainly affects the GI tract, it can also manifest as extraintestinal disorders. Up to $25 \%$ of

Address correspondence and reprint requests to Leonard B. Weinstock, MD Specialists in Gastroenterology, LLC 11525 Olde Cabin Road St. Louis, MO 63141 Phone: (314) 997-0554 Facsimile: (314) 997-5086 1w@ gidoctor.net. 
patients with CD develop extraintestinal disease manifestation or complications (4). Some of the extraintestinal complications of CD include skin, eye, and joint manifestations; gallstones; pancreatitis; nephrolithiasis; and amyloidosis (5). Systemic disease symptoms of $\mathrm{CD}$ include malnutrition and anemia (6). Iron deficiency is the main cause of anemia in CD as a consequence of dietary restrictions, malabsorption, and intestinal bleeding $(7,8)$. Furthermore, impaired iron absorption or increased loss of iron is correlated with disease activity and markers of inflammation in $\mathrm{CD}(6)$.

Iron deficiency may cause fatigue and sleep disorders, both of which are symptoms in patients with $\mathrm{CD}(9,10)$. Patients at risk of iron deficiency are also at risk for development of restless legs syndrome (RLS) (11). Restless legs syndrome is a central nervous system (CNS) disorder that elicits a compelling urge to move the legs at rest and contributes to sleep disturbances and poor quality of life. Restless legs syndrome may be primary (idiopathic and familial) or secondary to many disorders. Secondary RLS occurs in a variety of patient populations, including pregnant women and patients with end-stage renal failure, iron deficiency anemia, rheumatoid arthritis, diabetes, Parkinson's disease, or fibromyalgia (11-15). Gastric resection, chronic liver disease, and irritable bowel syndrome (IBS) have also been identified as secondary causes of RLS (16-18). Low brain iron concentrations associated with RLS may play a role in altered dopamine levels and may explain a unifying condition for most cases of RLS $(19,20)$.

Both CD and RLS have been associated with inflammation and bacterial overgrowth in the GI tract $(16,21)$. Antibacterial drugs such as rifaximin have been shown to be effective in treating bacterial overgrowth and GI symptoms in patients with CD $(22,23)$. In a prospective clinical trial, patients with IBS and concomitant RLS reported improvement from RLS baseline symptoms after treatment with rifaximin (16). Because both CD and RLS are associated with iron deficiency, inflammation, and bacterial overgrowth, this study was designed to investigate the potential link between these 2 disorders.

\section{MATERIALS AND METHODS}

\section{Study Design}

Adult patients with confirmed CD from 3 academic outpatient GI clinics, Weill Cornell Medical Center, Washington University School of Medicine, and Johns Hopkins School of Medicine from either August 2007 or February 2008 to March 2008, and 1 community GI clinic, Specialists in Gastroenterology from August 2007 to March 2008, were prospectively evaluated for the presence of RLS by a written survey provided by their gastroenterologist and completed by the patients. No patients were excluded or refused the survey.

\section{Assessments}

The diagnosis of RLS was made according to the following 4 criteria established by the international RLS study group: 1) an urge to move the legs, usually accompanied or caused by uncomfortable and unpleasant sensations in the legs; 2) the urge to move or unpleasant sensations begin or worsen during periods of rest or inactivity; 3 ) the urge to move or unpleasant sensations are partially relieved by movement, at least as long as the activity continues; and 4) the urge to move or unpleasant sensations are worse in the evening or night than during the day or only occur in the evening or night (24). Incidence of RLS was defined as the presence of RLS during any point in time, and prevalence was assessed as having RLS symptoms at the time the survey was completed. Prevalence of RLS in spouses of patients with $\mathrm{CD}$, as determined by patient query, was also assessed to provide a control group. Past and reported history of iron deficiency or anemia, onset and duration of RLS symptoms, clinical characteristics, RLS risk factors, and potential qualitative relationship 
between RLS and GI symptoms were queried. Statistical analysis using the chi-square test with $P<0.05$ was considered significant.

\section{RESULTS}

A total of 272 patients with $\mathrm{CD}$ were prospectively surveyed by gastroenterologists at Specialists in Gastroenterology ( $\mathrm{n}=135)$, Weill Cornell Medical Center $(\mathrm{n}=71)$, Washington University School of Medicine ( $\mathrm{n}=54)$, and Johns Hopkins School of Medicine $(\mathrm{n}=12)$. The number of patients recruited into the study by each institution was dependent on the time of study approval at that establishment. The institutional review board at 3 of the 4 institutions allowed the inclusion of risk factor questions in the survey. Because 1 center had insufficient data for some queries, the total number of patients surveyed differed per parameter in this study.

The incidence of RLS (the presence of RLS during any point in time) in patients with CD was $43 \%$ (93 of 218 patients). The prevalence of RLS in patients with CD was $30 \%$ ( 82 of 272 patients). Patients with CD and RLS were significantly older and less likely to have CD of the colon versus patients with CD but not RLS (Table 1). A primary risk factor of RLS, genetic predisposition, was assessed as the incidence of RLS in a first-degree relative and was not significantly different among patients with CD with or without RLS (12.0\% for both groups; Table 2). Although RLS symptoms in patients with CD were not associated with current iron deficiency ( $4.6 \%$ vs $4.7 \%$ for patients with and without RLS symptoms, respectively), the percentage of individuals with iron deficiency in the past was significantly higher in patients with CD and RLS than in patients with CD without RLS symptoms ( $49.3 \%$ vs $33.1 \%$, respectively; $P=0.031$ ). Other secondary RLS risk factors such as diabetes, rheumatologic condition, pregnancy, Parkinson's disease, and renal failure were not significantly different between patients with CD with or without RLS symptoms (Table 2).

In order to understand the prevalence of RLS in patients with CD with respect to the general population, the prevalence of RLS in the spouse control group was assessed by the patient survey. Patients with CD were more likely to have current RLS (82 of 272 [30\%]; CI 29.9\%-30.3\%) than their spouses (17 of 194 spouses [9\%]; CI 8.6\%-8.8\%; $P<0.0001$; Fig. 1). To identify potential comorbidity of RLS and CD conditions, patients were queried about the association of RLS and GI symptoms with respect to onset and qualitative symptom improvement. Sixty seven of 73 patients $(91.8 \%)$ with CD reported symptoms of RLS beginning during or after the onset of GI symptoms (Fig. 2). Among 72 patients with CD and RLS symptoms, $44.5 \%$ stated there was a correlation between qualitative RLS symptom improvement and overall CD symptom improvement.

\section{DISCUSSION}

In this prospective multicenter study, RLS was found to be a comorbid condition in patients with $\mathrm{CD}$, with an incidence of $43 \%$ and a prevalence of $30 \%$. The incidence of RLS in patients with $\mathrm{CD}$ reported in this study was greater than the incidence of many of the known extraintestinal manifestations of CD (5). The 9\% prevalence of RLS in the spouse control group was comparable with the prevalence in the general population $(24,25)$. Furthermore, RLS symptoms occurred during or after the onset of CD symptoms in the majority of patients, suggesting a link between CD and RLS. This association of RLS with CD may lead to an understanding of fatigue and sleep disturbances associated with $\mathrm{CD}(9)$.

Current systemic iron deficiency was not associated with RLS in patients with CD; however, iron deficiency in the past was reported in significantly more patients with CD and RLS than 
in those without RLS symptoms. This suggests that there may be additional factors other than iron deficiency that may be involved in RLS pathophysiology in these patients. Alternatively, CNS iron levels may not always correlate with total body iron concentrations, which may be more relevant to RLS.

Pathophysiology of CD includes small intestinal bacterial overgrowth (SIBO) and systemic inflammation. Previous studies demonstrated an association of SIBO with CD in the ileum $(22,26,27)$. The results in the current study suggest ileal involvement in patients with CD may be a risk factor for RLS. Also, gastric resection, chronic liver disease, and IBS have been identified as secondary causes of RLS (16-18). A recent study of patients with IBS and RLS reported improvement from RLS baseline symptoms after treatment with rifaximin, suggesting an association of RLS in IBS with SIBO (16). Furthermore, the recent finding of a link between RLS and SIBO supports the hypothesis that bacterial overgrowth may be a risk factor for RLS in patients with CD (28).

The inflammatory state associated with SIBO and CD stimulates proinflammatory cytokines $(1,29)$. Proinflammatory cytokines, such as interleukin-6 (IL-6), have been shown to increase production of a small peptide, hepcidin, which affects iron transport in in vitro models and in healthy human volunteers (30). We hypothesize that inflammation attributable to other systemic $(13,31)$ and GI-related disorders, such as CD, increases hepcidin levels. This results in an iron deficiency in the CNS, causing RLS. This may explain the increased prevalence of RLS in patients with multiple sclerosis (31) and rheumatoid arthritis $(13,31)$. A study to determine the efficacy of antibiotic therapy for primary RLS is ongoing. Monitoring hepcidin and IL-6 levels in response to antibiotic therapy for RLS associated with SIBO could further the understanding of RLS.

Weaknesses of the current study include the use of a non-validated written survey to assess RLS symptoms and the use of spouses as a comparative control group. However, diagnosis of RLS was established using the recommended 4 criteria established by the international RLS study group. In addition, the similarity between the prevalence of RLS reported in the spouse control group of this study and that in previous studies evaluating RLS prevalence in the general population supports the use of spouses as an appropriate control group.

Overall, RLS was found to be a common comorbid condition in patients with CD. Further studies are warranted to evaluate the potential impact that RLS has on quality of life in patients with CD using the international RLS rating scale.

\section{Acknowledgments}

The authors acknowledge the assistance of the DDRCC Morphology Core Facility at Washington University (DDRCC P30 DK52574). Editorial assistance was provided under the direction of the authors by MedThink Communications with support from Salix Pharmaceuticals, Inc.

\section{REFERENCES}

1. Baumgart DC, Carding SR. Inflammatory bowel disease: cause and immunobiology. Lancet. 2007; 369:1627-1640. [PubMed: 17499605]

2. Loftus EVJ, Schoenfeld P, Sandborn WJ. The epidemiology and natural history of Crohn's disease in population-based patient cohorts from North America: a systematic review. Aliment Pharmacol Ther. 2002; 16:51-60. [PubMed: 11856078]

3. Shanahan F. Crohn's disease. Lancet. 2002; 359:62-69. [PubMed: 11809204]

4. Baumgart DC, Sandborn WJ. Inflammatory bowel disease: clinical aspects and established and evolving therapies. Lancet. 2007; 369:1641-1657. [PubMed: 17499606] 
5. Rothfuss KS, Stange EF, Herrlinger KR. Extraintestinal manifestations and complications in inflammatory bowel diseases. World J Gastroenterol. 2006; 12:4819-4831. [PubMed: 16937463]

6. Kulnigg S, Gasche C. Systematic review: managing anaemia in Crohn's disease. Aliment Pharmacol Ther. 2006; 24:1507-1523. [PubMed: 17206940]

7. Gisbert JP, Gomollon F. Common misconceptions in the diagnosis and management of anemia in inflammatory bowel disease. Am J Gastroenterol. 2008; 103:1299-1307. [PubMed: 18477354]

8. Rockey DC. Occult gastrointestinal bleeding. N Engl J Med. 1999; 341:38-46. [PubMed: 10387941]

9. Ranjbaran Z, Keefer L, Farhadi A, et al. Impact of sleep disturbances in inflammatory bowel disease. J Gastroenterol Hepatol. 2007; 22:1748-1753. [PubMed: 17914945]

10. Murch SH. Local and systemic effects of macrophage cytokines in intestinal inflammation. Nutrition. 1998; 14:780-783. [PubMed: 9785361]

11. Patrick L. Restless legs syndrome: pathophysiology and the role of iron and folate. Altern Med Rev. 2007; 12:101-112. [PubMed: 17604457]

12. Merlino G, Fratticci L, Valente M, et al. Association of restless legs syndrome in type 2 diabetes: a case-control study. Sleep. 2007; 30:866-871. [PubMed: 17682657]

13. Hening WA, Caivano CK. Restless legs syndrome: a common disorder in patients with rheumatologic conditions. Semin Arthritis Rheum. 2008; 38:55-62. [PubMed: 17977584]

14. Yunus MB, Aldag JC. Restless legs syndrome and leg cramps in fibromyalgia syndrome: a controlled study. BMJ. 1996; 312:1339. [PubMed: 8646049]

15. Barone $\mathrm{P}$, Amboni M, Vitale $\mathrm{C}$, et al. Treatment of nocturnal disturbances and excessive daytime sleepiness in Parkinson's disease. Neurology. 2004; 63:S35-38. [PubMed: 15505142]

16. Weinstock LB, Fern SE, Duntley SP. Restless legs syndrome in patients with irritable bowel syndrome: response to small intestinal bacterial overgrowth therapy. Dig Dis Sci. 2008; 53:12521256. [PubMed: 17934858]

17. Banerji NK, Hurwitz LJ. Restless legs syndrome, with particular reference to its occurrence after gastric surgery. Br Med J. 1970; 4:774-775. [PubMed: 5497406]

18. Franco RA, Ashwathnarayan R, Deshpandee A, et al. The high prevalence of restless legs syndrome symptoms in liver disease in an academic-based hepatology practice. J Clin Sleep Med. 2008; 4:45-49. [PubMed: 18350962]

19. Connor JR, Boyer PJ, Menzies SL, et al. Neuropathological examination suggests impaired brain iron acquisition in restless legs syndrome. Neurology. 2003; 61:304-309. [PubMed: 12913188]

20. Allen R. Dopamine and iron in the pathophysiology of restless legs syndrome (RLS). Sleep Med. 2004; 5:385-391. [PubMed: 15222997]

21. Sartor RB. Bacteria in Crohn's disease: mechanisms of inflammation and therapeutic implications. J Clin Gastroenterol. 2007; 41(suppl 1):S37-S43. [PubMed: 17438417]

22. Biancone L, Vernia P, Agostini D, et al. Effect of rifaximin on intestinal bacterial overgrowth in Crohn's disease as assessed by the H2-Glucose Breath Test. Curr Med Res Opin. 2000; 16:14-20. [PubMed: 16422030]

23. Shafran I, Johnson LK. An open-label evaluation of rifaximin in the treatment of active Crohn's disease. Curr Med Res Opin. 2005; 21:1165-1169. [PubMed: 16083525]

24. Rama AN, Kushida CA. Restless legs syndrome and periodic limb movement disorder. Med Clin North Am. 2004; 88:653-667. [PubMed: 15087209]

25. Allen RP, Walters AS, Montplaisir J, et al. Restless legs syndrome prevalence and impact: REST general population study. Arch Intern Med. 2005; 165:1286-1292. [PubMed: 15956009]

26. Baumgart M, Dogan B, Rishniw M, et al. Culture independent analysis of ileal mucosa reveals a selective increase in invasive Escherichia coli of novel phylogeny relative to depletion of Clostridiales in Crohn's disease involving the ileum. Isme J. 2007; 1:403-418. [PubMed: 18043660]

27. Sartor RB. Microbial influences in inflammatory bowel diseases. Gastroenterology. 2008; 134:577-594. [PubMed: 18242222]

28. Weinstock L. Rifaximin improves restless legs syndrome associated with small intestinal bacterial overgrowth [poster]. American College of Gastroenterology Annual Scientific Meeting. 2008 
29. Lin HC. Small intestinal bacterial overgrowth: a framework for understanding irritable bowel syndrome. JAMA. 2004; 292:852-858. [PubMed: 15316000]

30. Nemeth E, Rivera S, Gabayan V, et al. IL-6 mediates hypoferremia of inflammation by inducing the synthesis of the iron regulatory hormone hepcidin. J Clin Invest. 2004; 113:1271-1276. [PubMed: 15124018]

31. Auger C, Montplaisir J, Duquette P. Increased frequency of restless legs syndrome in a FrenchCanadian population with multiple sclerosis. Neurology. 2005; 65:1652-1653. [PubMed: 16301499] 


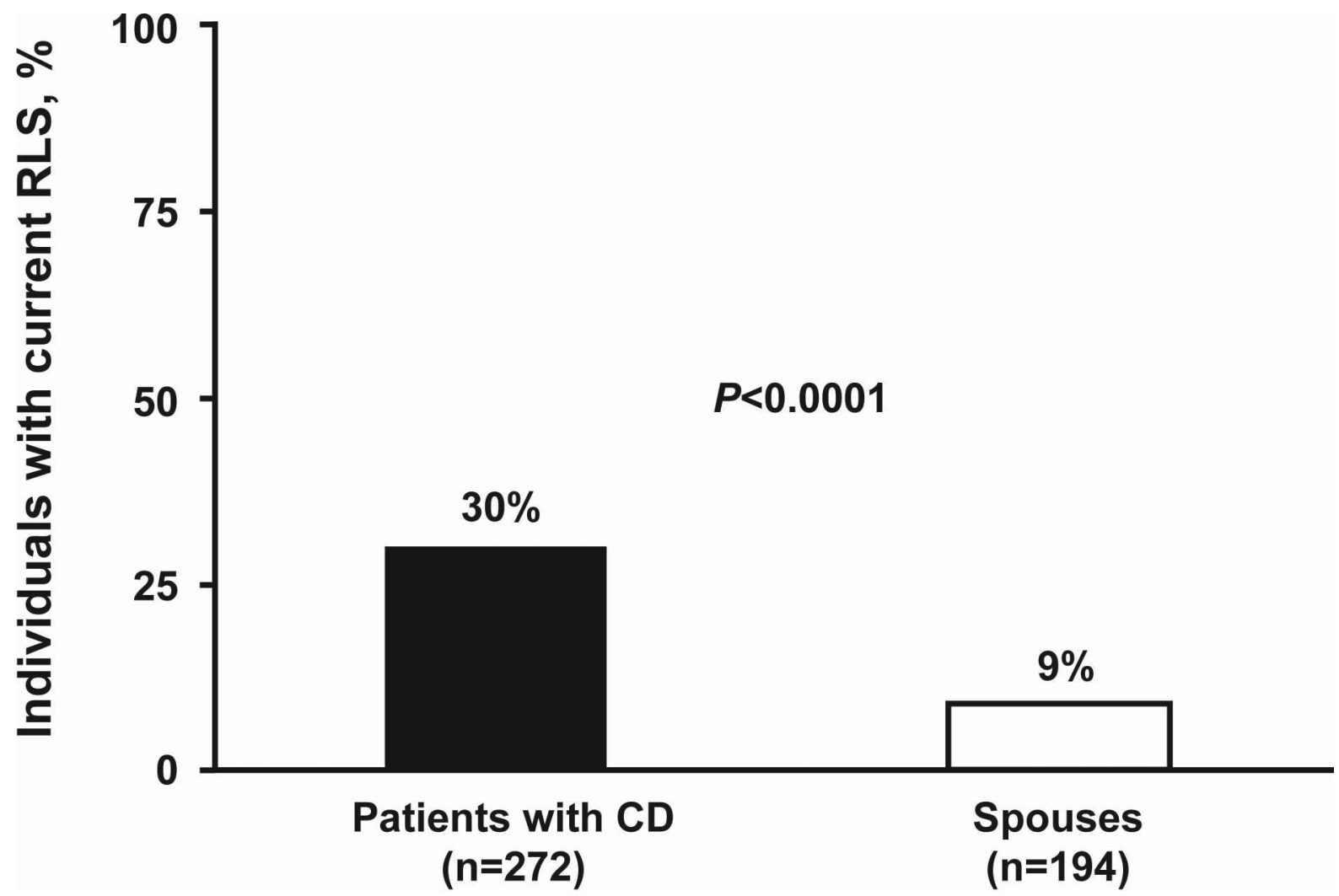

FIGURE 1.

Restless legs syndrome (RLS) prevalence in patients with Crohn's disease (CD) and their spouses. Patients with CD were more likely to have current RLS (82 of 272 patients, 30\%) than their spouses (17 of 194 spouses, $9 \% ; P<0.0001$ ). 


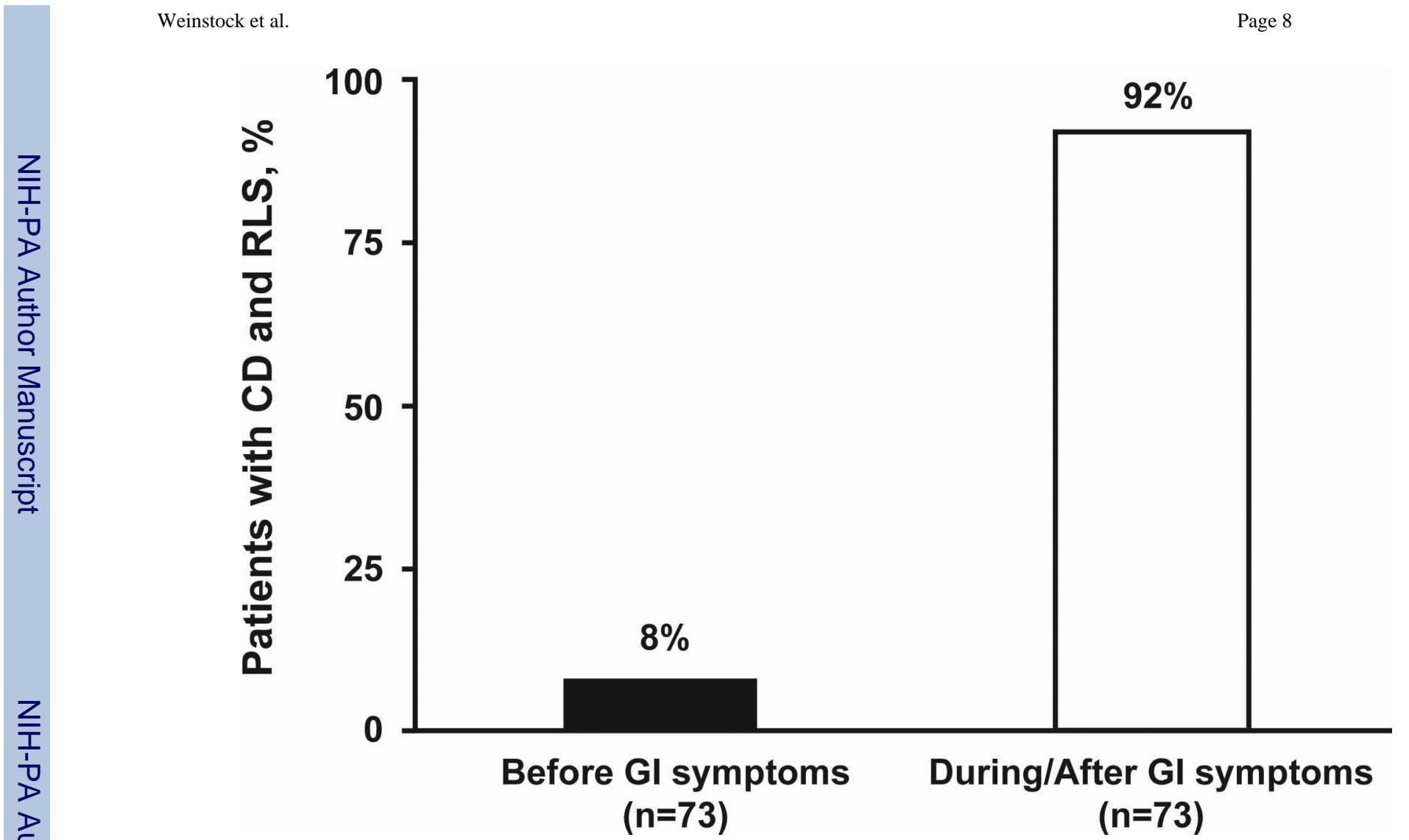

FIGURE 2.

Percentage of patients with Crohn's disease (CD) describing onset of restless legs syndrome (RLS) symptoms before versus during/after onset of gastrointestinal (GI) symptoms.

Substantially more patients with CD reported onset of RLS during or after GI symptoms. 
TABLE 1

Patient Demographics and Clinical Characteristics

\begin{tabular}{|c|c|c|c|}
\hline Parameter & Patients With RLS $^{a, b}{ }_{(\mathrm{n}=93)}$ & Patients Without $\operatorname{RLS}^{b}(\mathrm{n}=179)$ & $P$ value \\
\hline Age, $y$, mean \pm SD (range) & $47 \pm 13(19-72)$ & $42 \pm 16(18-84)$ & 0.01 \\
\hline Male:Female, $\mathrm{n}$ & $40: 53$ & $81: 98$ & NS \\
\hline \multicolumn{4}{|l|}{ CD location, n $(\%)$} \\
\hline Small intestine involvement & $53 / 68(77.9)$ & $78 / 117(66.7)$ & NS \\
\hline Colonic involvement alone & $27 / 68(39.7)$ & $74 / 117(63.2)$ & 0.002 \\
\hline Currently taking iron supplementation, $\mathrm{n}(\%)$ & $10 / 67(14.9)$ & 14/118 (11.9) & NS \\
\hline
\end{tabular}


TABLE 2

RLS Risk Factor Characteristics

\begin{tabular}{|c|c|c|c|}
\hline Parameter, n (\%) & Patients With RLS ${ }^{a, b}$ n/n (\%) & Patients Without $\operatorname{RLS}^{b}$ n/n (\%) & $P$ value \\
\hline First-degree relative with RLS & $11 / 92(12.0)$ & 14/121 (11.6) & NS \\
\hline \multicolumn{4}{|l|}{ Iron deficiency } \\
\hline Current & $3 / 65(4.6)$ & $5 / 106(4.7)$ & NS \\
\hline Past & $34 / 69(49.3)$ & $39 / 118(33.1)$ & 0.031 \\
\hline \multicolumn{4}{|l|}{ History of } \\
\hline Type I diabetes & $3 / 69(4.3)$ & $3 / 118(2.5)$ & NS \\
\hline Fibromyalgia & $2 / 69(2.9)$ & $2 / 118(1.7)$ & NS \\
\hline Rheumatoid arthritis & $1 / 69(1.4)$ & $4 / 118(3.4)$ & NS \\
\hline Parkinson's disease & $0 / 68(0.0)$ & $2 / 118(1.7)$ & NS \\
\hline Renal failure & $0 / 67(0.0)$ & $1 / 118(0.8)$ & NS \\
\hline Currently pregnant & $0 / 53(0.0)$ & $3 / 116(2.6)$ & NS \\
\hline
\end{tabular}

NS, not significant; RLS, restless legs syndrome.

${ }^{a}$ Patients with RLS at any point in lifetime.

${ }^{b}$ Total number of patients surveyed differed per parameter due to insufficient data from 1 study center. 